\title{
Significance of timely reference on maternal morbidity and mortality
}

\author{
Piyusha Chandrayan*, Rohit K. Merawat, Usha P. Parekh
}

Department of Obstetrics and Gynecology, Sumandeep Vidyapeeth University, Vadodara, Gujarat, India

Received: 06 July 2018

Accepted: 28 August 2018

\section{*Correspondence:}

Dr. Piyusha Chandrayan,

E-mail: piyusha011@gmail.com

Copyright: ( $\odot$ the author(s), publisher and licensee Medip Academy. This is an open-access article distributed under the terms of the Creative Commons Attribution Non-Commercial License, which permits unrestricted non-commercial use, distribution, and reproduction in any medium, provided the original work is properly cited.

\section{ABSTRACT}

Background: The objective is to evaluate the effectiveness of the timely maternal referral system to a tertiary care centre in reducing maternal morbidity and mortality. Well known causes of maternal mortality are delays at three levels: in seeking care, in referring/reaching health facility in time and in receiving adequate treatment. In this study, authors have made an attempt to focus mainly on the referral system in improving maternal morbidity and mortality.

Methods: This was an observational study, conducted at Dhiraj General Hospital, a rural tertiary health care facility, affiliated to SBKSMC and RC located in Waghodia district, $16 \mathrm{kms}$ away from the Vadodara city. It covers an area of around 7,550 sq kms of rural areas. All the patients referred from any centre and admitted to emergency obstetrical ward were included under the study within the study time period.

Results: The total incidence of referred patients in this study accounted for $7.49 \% .70 \%$ of the patients under study were unbooked. $65 \%$ of the referrals were multigravida. 35\% of the patients were of age group 24-29 yrs. Hemorrhage, accounting 39\% was the most common cause of referral. The bulk of referrals, $70 \%$ were within the $50 \mathrm{~km}$ circumference. $65 \%$ of present referred cases reached within 5 hours from the referring centre due to timely referral and easy accessibility of the transport system like - availability of 108 .

Conclusions: Timely referrals of women have significantly reduced the maternal morbidity and mortality as patients from remote area can avail tertiary medical health facilities. A proper referral letter with primary care from the referring centre can further enhance the functioning of this system.

Keywords: Maternal mortality, Morbidity, Referral system, Tertiary Centre, Transportation

\section{INTRODUCTION}

Death of a woman while pregnant or within 42 days of the termination of pregnancy irrespective of the duration and the site of pregnancy, from any cause related to or aggravated by the pregnancy or its management but not from accidental or incidental causes is known as Maternal Mortality. ${ }^{1}$

Maternal Mortality Ratio (MMR): The MMR is expressed in terms of such maternal deaths per 100,000 live births. In most of the developed countries, the MMR varies from $4-40$ per 100,000 live births. In the developing countries, it varies from 100-700 with India having about 254 per 100,000 live births. ${ }^{1,2}$ According to WHO, India's maternal mortality rate (MMR), declined by $16 \%$ in $2011-12 .^{3}$ The fifth Millennium Development Goal of reducing maternal mortality to 109 per $1,00,000$ live births however, by 2015 could not be achieved. ${ }^{4}$

The outcome of $5^{\text {th }}$ Millennium Developmental Goal related to maternal mortality as per WHO is: ${ }^{4}$

Since 1990 , the maternal mortality ratio has declined by 45 per cent worldwide, and most of the reduction has occurred since 2000 . 
- In Southern Asia, the maternal mortality ratio declined by 64 per cent between 1990 and 2013, and in sub-Saharan Africa it fell by 49 per cent.

- More than 71 per cent of births were assisted by skilled health personnel globally in 2014, an increase from 59 per cent in 1990.

Well known causes of maternal mortality are delays at three levels:

1. In seeking care

2. In referring/reaching health facility in time

3 . In receiving adequate treatment.

In this study, authors have made an attempt to focus mainly on the referral system in improving maternal morbidity and mortality.

Morbidity criteria: Maternal morbidity originates from any cause related to pregnancy or its management any time during antepartum, intrapartum and postpartum period usually up to 42 days after confinement. ${ }^{1}$

The parameters of maternal morbidity are:

1. Fever more than $100.4^{\circ} \mathrm{F}$ or $38^{\circ} \mathrm{C}$ and continuing more than 24 hours,

2. Blood pressure more than $140 / 90 \mathrm{~mm}$ of $\mathrm{Hg}$,

3. Recurrent vaginal bleeding,

4. $\mathrm{Hb} \%$ less than $10.5 \mathrm{~g}$ irrespective of gestational period,

5. Asymptomatic bacteriuria of pregnancy. ${ }^{1}$

In the literature reviewed to date, there is lack of a common definition, identification criteria, standardized assessment tools and common indicators to measure maternal morbidity. Researchers have utilized maternal morbidity definitions of varying severities that range from less severe complications of pregnancy and extend to near miss morbidity.

According to present institution the criteria for morbidity includes:

1. ICU admission-with or without ventilator support

2. Massive Blood Transfusion required

3. Major organ derangement.

The aims and objectives are, to evaluate the effectiveness of the timely maternal referral system to a tertiary care centre in reducing maternal morbidity and mortality. The evaluation was performed on basis of emergency admissions in labour ward of Dhiraj General Hospital after being referred.

Distribution of the patients according to gravidity, age, distance from the referring centre and time for transportation is tabulated and evaluated. Enhancing the significance of timely referral with proper referral letter.

\section{METHODS}

This was an observational study, conducted at Dhiraj General Hospital, a rural tertiary health care facility, affiliated to SBKSMC and RC located in Waghodia district, $16 \mathrm{kms}$ away from the Vadodara city. It covers nearly an area of around 7,550 sq kms of rural areas. The period of study was one year (March 2016 to March 2017).

Referral system: Referral is the process by which a health taker seeks consultation with or transfer of clinical responsibility to another practitioner at a higher medical health service centre for a condition affecting the patient with proper detailed letter. ${ }^{5}$ It ensures the accessibility of medical care to the patients from the community or primary level to tertiary health care facilities.

Sources of referral at present centre:

- $\quad$ PHC-include the areas under Kalurgam, Ras, Kheda, Anklav.

- CHC-include Por.

- Private institutions.

\section{Inclusion criteria}

- All women of reproductive age group booked or unbooked admitted in emergency to labour ward as intranatal, antenatal, postnatal or post abortal with a referral slip.

\section{Exclusion criteria}

- Patient of gynaecological complaints.

- All other obstetrics patients without referral letter.

\section{RESULTS}

- Total no. of admissions in obstetrics during the study $=2828$

- Total no. of received referral cases $=212$

- $\quad$ Incidence $=7.49 \%$.

Referral percentage

- Total no. of referrals $=212$

- No. of morbid patients $=52$

- Total percentage of morbidity $=24.5 \%$

- $\quad$ Total percentage of mortality ( 1$)=0.4 \%$.

As demonstrated in this Figure 1, most of the patients in this study i.e., $65 \%$ were Multigravida whereas 35\% consisted of primigravida.

In this study, it has been observed that complications causing referral were more in case of multigravida due to low socio-economic status of the patients and high parity. 


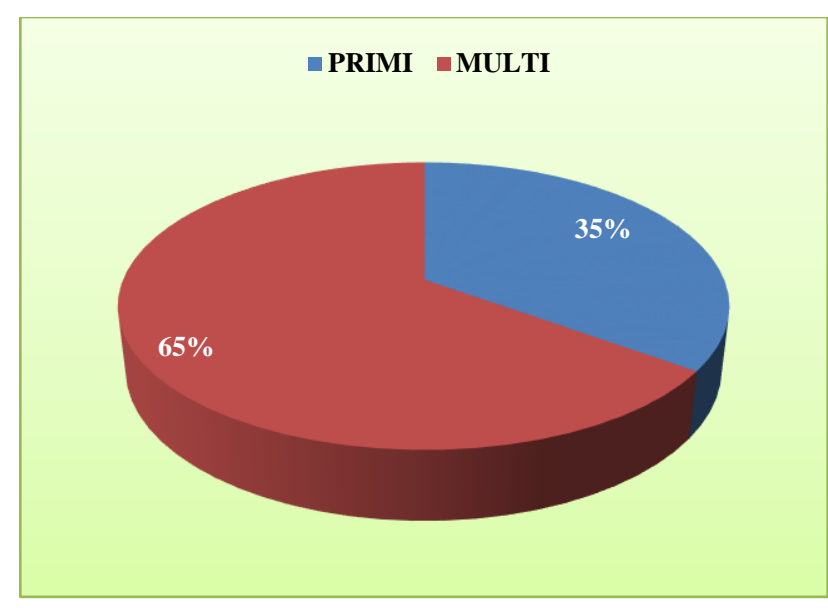

Figure 1: Distribution according to parity.

As per Table 1; the maximum referrals received, $35 \%$ were in the reproductive age group of 24-29 years followed by $30 \%$ in the age group of 18-23 years and $22 \%$ in the $30-35$ years; constituting total of $85 \%$. Extremes of ages constituted only $1 \%$ of the referrals.

Table 1: Distribution according to age.

\begin{tabular}{|l|l|}
\hline Age & Percentage \\
\hline $18-23$ years & 30 \\
\hline $24-29$ years & 35 \\
\hline $30-35$ years & 22 \\
\hline $36-41$ years & 12 \\
\hline 42 and above & 1 \\
\hline
\end{tabular}

As per Table 2; hemorrhage accounted for the most percentage of referrals $39 \%$, followed by abnormal presentation including cephalo pelvic disproportion $15 \%$. Due to the availability of functional blood bank and ICU facility the antepartum and postpartum hemorrhage patients could be managed within time.

Table 2: Distribution according to causes of referral.

\begin{tabular}{|ll|}
\hline Causes of referral & Percentage \\
\hline Hemorrhage & 39 \\
\hline - $\quad$ APH & 10 \\
\hline PPH $\quad$ Incomplete abortion & 18 \\
\hline $\begin{array}{l}\text { CPD/ abnormal presentation/ obstructed } \\
\text { labor/ FD }\end{array}$ & 11 \\
\hline Pre-eclampsia & 15 \\
\hline Previous LSCS in labor & 14 \\
\hline Eclampsia & 10 \\
\hline Medical disorders like jaundice, malaria & 5 \\
\hline Surgical complications like acute abdomen & 5 \\
\hline PROM & 2 \\
\hline Rupture uterus/ perforation & 1 \\
\hline
\end{tabular}

Patient referred as a case of acute abdomen on day 2 following suction and evacuation. Patient underwent $2^{\text {nd }}$ trimester abortion due to missed abortion at 13 weeks of gestation at some Private institution. On ultrasonography, perforation was present on the anterior wall of uterus with strangulation of bowel loop in that perforation leading to intestinal obstruction. On laprotomy, A: single uterine perforation on anterior wall of uterus measuring $2 * 2 \mathrm{~cm}$ confirmed and sutured. B: The necrosed bowel segment resected followed by end to end anastomosis. Ileostomy was done. Post operatively patient was stable.

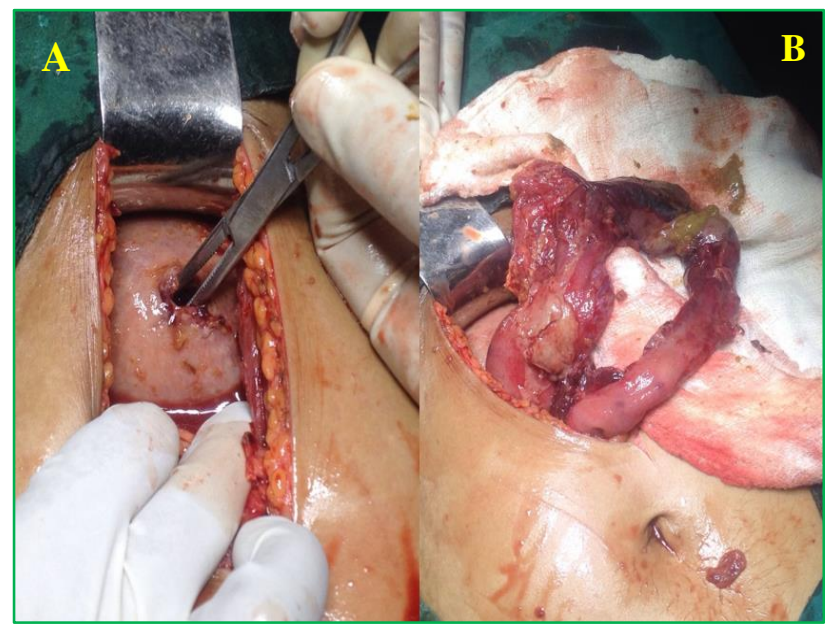

Figure 2: Case of uterine perforation followed by suction and evacuation.

Patient referred with a referral slip- diagnosed as a case of abruptio placentae + IUD + previous LSCS. Her gestational age was 37 weeks. Patient was a known case of pre-eclampsia and was on anti-hypertensive Labetalol $100 \mathrm{mg}$ bid. On admission- blood tinged urine was present. Membranes were absent, and bleeding was present per-vaginally. The patient was in a state of shock. On ultrasonography- a retroplacental clot of size $5 * 6 \mathrm{~cm}$ was confirmed with fetal demise. Emergency LSCS was planned for obstructed labour. Intra operativelycorvillinear uterus with multiple hemorrhagic spots was found. 2 units PCV and FFP was given. Patient was stable post operatively.

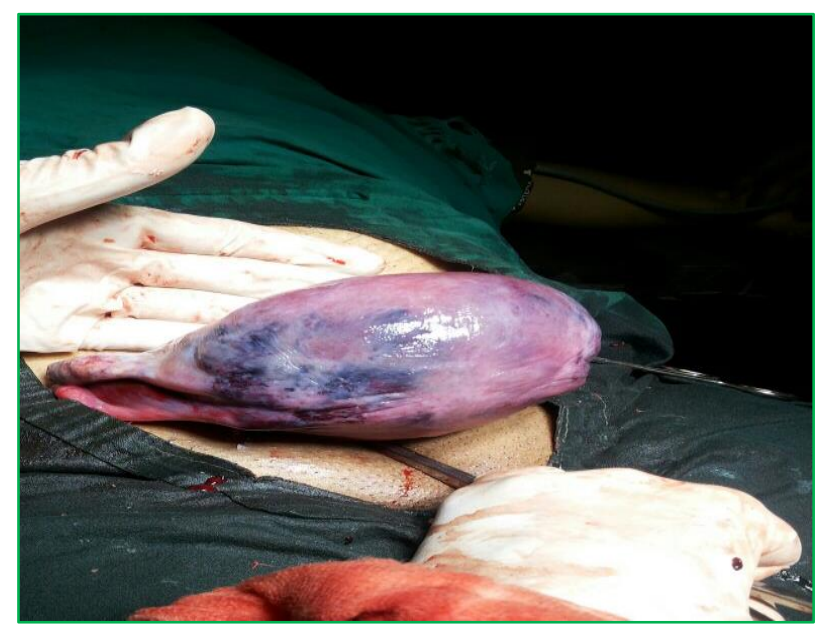

Figure 3: Case of abruptio placenta. 
As per Table 3; Bulk of the referrals obtained in this study was within $50 \mathrm{kms}$ i.e., $70 \%$. This was mainly due to location of this hospital nearly $16 \mathrm{kms}$ from the main city. And proximity to nearby PHC's and CHC's.

Table 3: Distribution according to distance from referral centre.

\begin{tabular}{|lll|}
\hline Distance & Number & Percentage \\
\hline$<50 \mathrm{~km}$ & 148 & 70 \\
\hline $51-100 \mathrm{~km}$ & 35 & 16.5 \\
\hline$>100 \mathrm{~km}$ & 24 & 13.5 \\
\hline Total & 212 & 100 \\
\hline
\end{tabular}

As evident from Table 4; the maximum referral that could reach this hospital was within 5 hrs. This was mainly due to the proximity of this hospital from nearby rural areas as well due to availability of 108 ambulance.
Table 4: Distribution according to time from referral centre.

\begin{tabular}{|lll|}
\hline \multicolumn{3}{|c|}{ Time taken for transportation } \\
\hline Duration & Number & Percentage \\
\hline$<5$ hours & 120 & 56.6 \\
\hline 5-10 hours & 82 & 38.6 \\
\hline$>10$ hours & 10 & 4.7 \\
\hline Total & 212 & 100 \\
\hline
\end{tabular}

As shown in Table 5; the lesser was the time taken by the patient to each this hospital the better was the recovery percentage. The more was the time taken to refer the patient increased the morbidity and mortality percentage accounting to $70 \%$ and $0.4 \%$ respectively. Hence, it is necessary to realize the cases to be referred as soon as possible and referring these cases to the tertiary centre with a proper referral note.

Table 5: Outcome in terms of morbidity and mortality.

\begin{tabular}{|llllll|}
\hline Time taken & & & & & \\
\hline Duration & Number & Percentage & Number of morbidity & Percentage of morbidity & Percentage of mortality \\
\hline$<5$ hours & 120 & 56.6 & 25 & 20.8 & 0 \\
\hline 5- 10 hours & 82 & 38.6 & 20 & 24.3 & 0 \\
\hline$>10$ hours & 10 & 4.7 & 7 & 70 & 0.4 \\
\hline Total & 212 & 100 & 52 & - & - \\
\hline
\end{tabular}

\section{DISCUSSION}

$70 \%$ of the patients were unbooked at present institution. Only $10 \%$ of the patients were booked at any health care facility. This shows the negligence towards ANC visits inspite of Government schemes like Janani Surekhsa Yogna and availability of trained Aganwadi workers. ${ }^{6}$ As per a study on, "Innovations and Challenges in Reducing Maternal Mortality in Tamil Nadu, in 2007"Early ANC visits may identify some problems of pregnancy early, which will help the ANM to refer the mother in advance to a higher institution for timely intervention. $^{7}$

$65 \%$ of the referrals were multigravida. This was mainly due to the fact that incidence of hemorrhage including; antepartum, postpartum and others is more common in these patients. Most of these patients were in the age group of 24-29 years. This is in par with the study conducted by Sharafat $\mathrm{Z}$ et al. ${ }^{8}$

Hemorrhage, accounting 39\% was the most common cause of referral. Most of the cases of hemorrhage required immediate surgical intervention and transfusion of blood products. As this hospital is a tertiary health care with availability of blood bank, and well-equipped ICU facilities. These referred patients could be managed within time. Same observation was made as per a study on, "Maternal Mortality-reduction Programme in Andhra Pradesh in 2007, where haemorrhage was the main cause of maternal morbidity and mortality". ${ }^{9}$

The bulk of referrals, $70 \%$ were within the $50 \mathrm{kms}$ circumference. This was mainly due to close proximity of this hospital to nearby rural areas. $65 \%$ of present referred cases reached within 5 hours from the referring centre due to timely referral and easy accessibility of the transport system like - availability of 108 .

The same was seen in a study "On maternal mortality in AP in 2007", and it reported that survivors were successful in seeking and obtaining treatment in time compared to death cases due to implementation of hospital ambulance and $108 .^{9}$

However, the cases which reached too late had a poorer prognosis with more hospital stay and increased morbidity and mortality.

The same was concluded in the article, "The effectiveness of emergency obstetric referral interventions in developing country settings, in 2012"-delayed referral was a leading cause of maternal morbidity in developing countries. $^{10}$ 
Keynote: The referred patient should be explained the seriousness of the condition before being referred. A proper method of transportation should be made available at primary health centres along with trained personnels. A telephonic conversation can be made to the respective doctor before referral.

\section{CONCLUSION}

Timely referrals of women have significantly reduced the maternal morbidity and mortality as patients from remote area can avail tertiary medical health facilities. A proper referral letter with primary care from the referring centre can further enhance the functioning of this system. All clinical staff must undertake regular, written, documented and audited training for the identification and initial management of serious obstetric conditions or emerging potential emergencies in order to do timely reference.

Funding: No funding sources Conflict of interest: None declared

Ethical approval: The study was approved by the Institutional Ethics Committee

\section{REFERENCES}

1. Konar H. DC Dutta's textbook of obstretics. $7^{\text {th }}$ ed. JP Medical Ltd; 2013: 602-603.

2. Maternal mortality in India: 1997-2003 trends, causes and risk factors. New Delhi, Registrar General of India, 2006. Available at: http://www.cghr.org/wordpress/wpcontent/uploads/RGI-CGHR-Maternal-Mortality-inIndia-1997\%E2\%80\%932003.pdf.
3. World Health Organization. Maternal mortality in 2000: estimates developed by UNICEF and UNFPA. Geneva: World Health Organization, 2007;4:16. Available at: www. who. int/reproductivehealth/MNBH/maternal mortality 2000/index.html.

4. The United Nations' Millennium Development Goals Report 2015. Available at: www.mdgmonitor.org.

5. Park, K. Park's textbook of preventive and social medicine-India. Jabalpur: Banarsidas Bhanot Publishers; 2007: 741.

6. Pradhan Mantri Surakshit Matritva Abhiyan. Available at: https://pmsma.nhp.gov.in/about-scheme

7. Padmanaban P, Raman PS, Mavalankar DV. Innovations and challenges in reducing maternal mortality in Tamil Nadu, India. J Health Population Nutr. 2009;27(2):202-19.

8. Sharafat Z. A Survey of Pregnancies Complicated by Antepartum Haemorrhage. Medical Forum Monthly. 2014.

9. Prakasamma M. Maternal mortality-reduction programme in Andhra Pradesh. J Health Population Nutr. 2009;27(2):220-234.

10. Hussein J, Kanguru L, Astin M, Munjanja S. The effectiveness of emergency obstetric referral interventions in developing country settings: a systematic review. PLoS Med. 2012;9(7):e1001264.

Cite this article as: Chandrayan P, Merawat RK, Parekh UP. Significance of timely reference on maternal morbidity and mortality. Int J Reprod Contracept Obstet Gynecol 2018;7:3985-9. 